\title{
Crush Grinding
}

Federal Manufacturing \& Technologies

T. Q. Nguyen

Department ME7

KCP-613-7032

Distributed April 2005

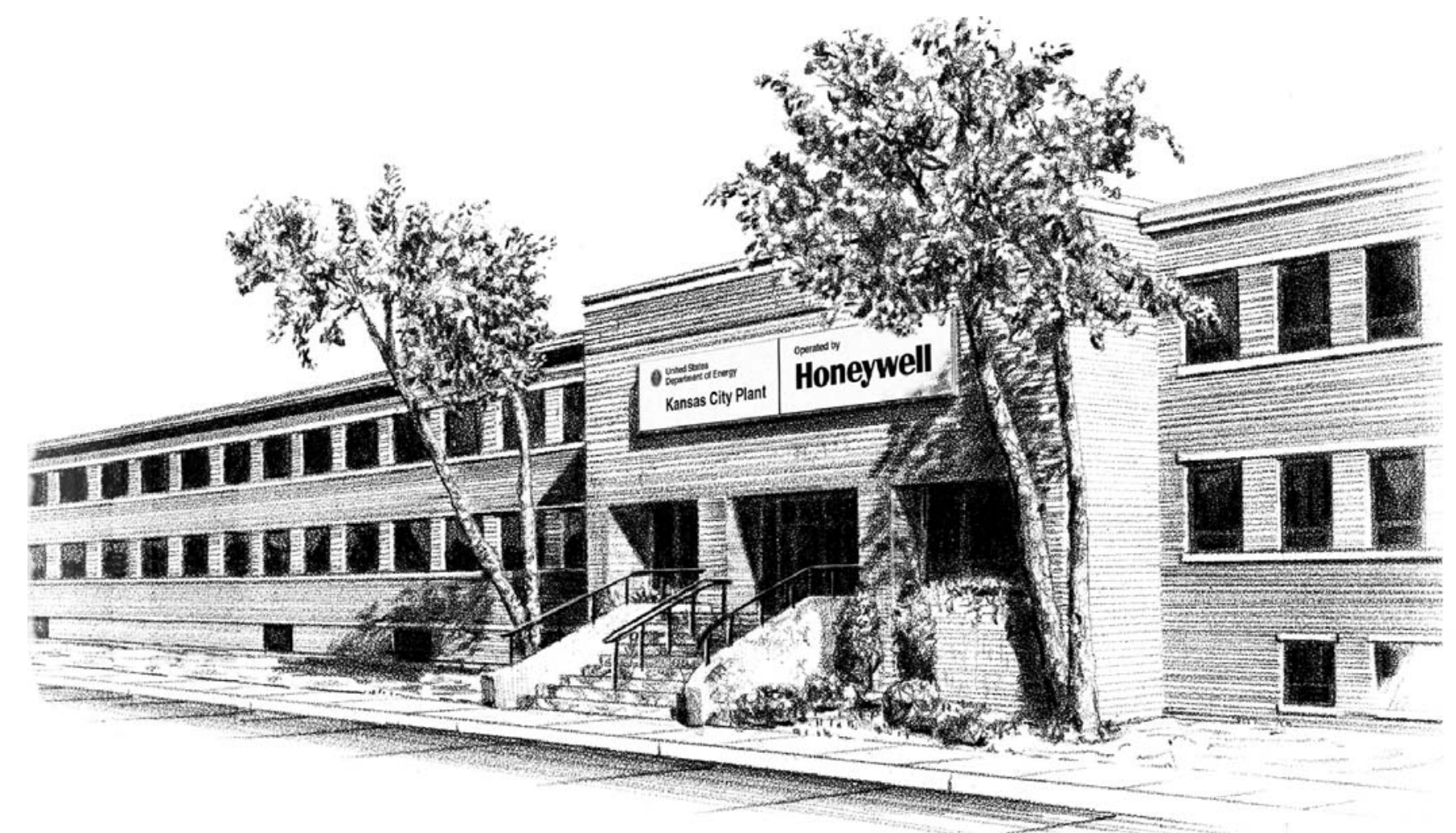

Prepared under prime contract DE-ACO4-01AL66850 for the United States Department of Energy 


\section{DISCLAIMER}

This report was prepared as an account of work sponsored by an agency of the United States Government. Neither the United States Government nor any agency thereof, nor any of their employees, makes any warranty, express or implied, or assumes any legal liability or responsibility for the accuracy, completeness, or usefulness of any information, apparatus, product, or process disclosed, or represents that its use would not infringe privately owned rights. Reference herein to any specific commercial product, process or service by trade names, trademark, manufacturer, or otherwise, does not necessarily constitute or imply its endorsement, recommendation or favoring by the United States Government or any agency thereof. The views and opinions of authors expressed herein do not necessarily state or reflect those of the United States Government or any agency thereof.

All data prepared, analyzed and presented has been developed in a specific context of work and was prepared for internal evaluation and use pursuant to that work authorized under the reference contract. Reference herein to any specific commercial product, process or service by trade name, trademark, manufacturer, or otherwise, does not necessarily constitute or imply its endorsement, recommendation or favoring by the United States Government, any agency thereof or Honeywell Federal Manufacturing \& Technologies, LLC.

Printed in the United States of America.

This report has been reproduced from the best available copy.

Available to DOE and DOE contractors from the Office of Scientific and Technical Information, P.O. Box 62, Oak Ridge, Tennessee 37831; prices available from (865) 576-8401, FTS 626-8401.

Available to the public from the National Technical Information Service, U.S. Department of Commerce, 5285 Port Royal, Rd., Springfield, Virginia 22161, (703) 487-4650.

A prime contractor with the United States Department of Energy under Contract Number DE-AC04-O1AL66850

\author{
Honeywell Federal Manufacturing \& Technologies \\ P.O. Box 419159 \\ Kansas City, Missouri, 64141-6159
}




\section{Honeywell}

\section{KCP-613-7032 \\ Distribution Category UC-42}

Approved for public release; distribution is unlimited.

\section{CRUSH GRINDING}

T. Q. Nguyen

Department ME7

KCP-613-7932

Distributed April 2005

Project Team:

Tony Nguyen

Karl Arnold 



\section{Contents}

Section Page

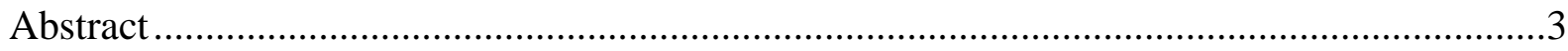

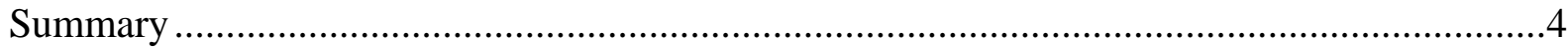

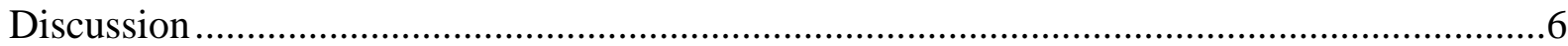

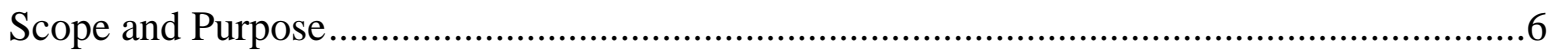

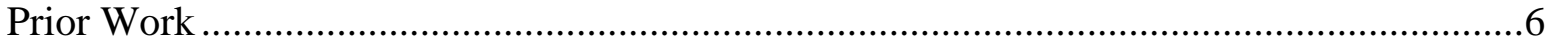

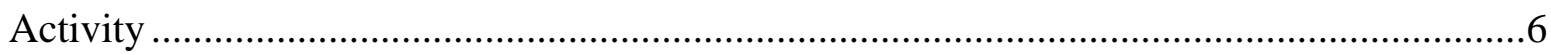

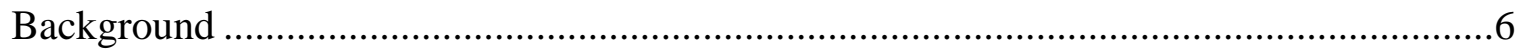

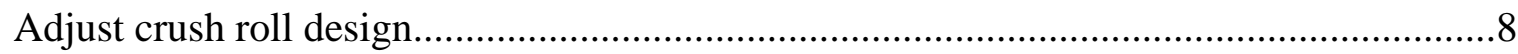

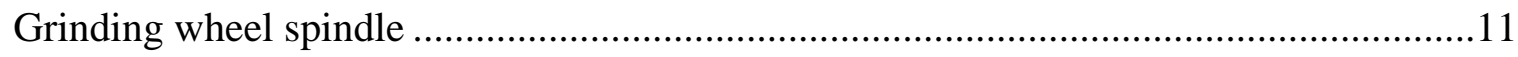

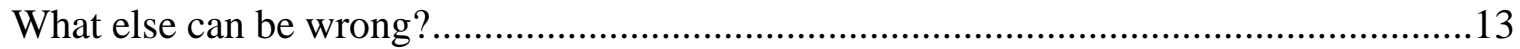

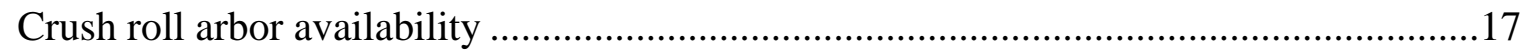

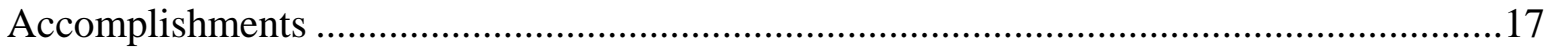

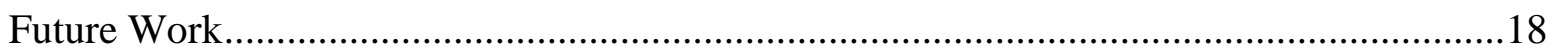

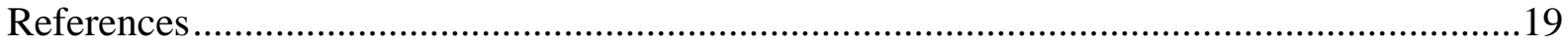

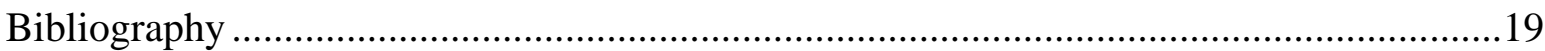




\section{Illustrations}

Figure Page

Figure 1 A record of instruction in 1989 to handle swelling of stem. …...............................7

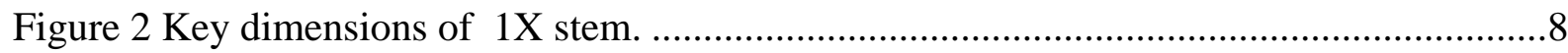

Figure 3 Surface definition and relationship. Surface A \& B are coupled - the distance will not change. Surface $\mathrm{C}$ is decoupled to A \& B -

Distance from surface $\mathrm{C}$ to surface $\mathrm{A}$ (or $\mathrm{B}$ ) will increase during the transformation of crush grinding. ................................................................. 10

Figure 4 Illustration of total (build-up) tolerance in the worst case of assembly...................11

Figure 5 Schematic of the crush grinding principle.....................................................12

Figure 6 The effect of misalignment on the grinding wheel.............................................13

Figure 7 Illustration of ground surface. Non-uniform material is believed to

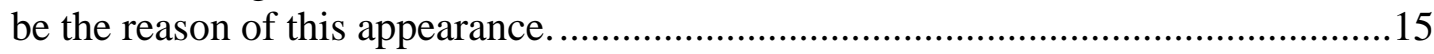

\section{Tables}

Number Page

Table 1 Measurements of specimen using old crush roll TC458347-001.Error! Bookmark not defined.

Table 2 Measurement of adjusted dimensions for crush roll TC423230-004.Error! Bookmark not defined. 


\begin{abstract}
Crush Grinding is a special process used at the Kansas City Plant to finish stem sections of reservoir products. In this process, a precise profile of the desired product is formed on a tungsten carbide roll. This roll slowly transfers a mirror image of the profile onto the grinding surface of a wheel. The transfer rate of the profile is between 0.001 and 0.010 inches per minute. Crush grinding is desirable since it provides consistent surface finishes and thin walls at a high production rate. In addition, it generates very sharp fillet radii. However, crush grinding is a complex process since many variables affect the final product. Therefore, the process requires more attention and knowledge beyond basic metal removal practices. While the Kansas City Plant began using these machines in 1995, a formal study regarding crush grinding has not been conducted there. In addition, very little literature is available in the grinding industry regarding this process. As a result, new engineers at the Kansas City Plant must learn the process through trial and error. The purpose of this document is to address this literature deficit while specifically promoting a better understanding of the stem crush grinding process at the Kansas City Plant.
\end{abstract}




\section{Summary}

In August 2002, machinists in D/025 were constantly adjusting the grinder to hold the stem in tolerance. The $1 \mathrm{X}$ body was the most complicated configuration to process since its stem (the longest of any configuration) and three diameters had to be ground at the same time. In addition, the stem was usually swollen in the middle. The only method to control this condition was to adjust the grinder until the measured difference in diameter along the stem was 0.0018 inches or larger than both ends of the stem. In other cases, the stem was large on both ends and necked in the middle. Sometimes, the groove's width would be too wide or its lateral position would grow or shrink. Over time, all corners and radii processed on the stems wore faster due to the deteriorating condition of the grinder.

Machine logs indicated that some of the process problems had occurred intermittently throughout the entire time the Kansas City Plant (KCP) had been grinding stems. To manage the schedule and machine availability, the grinder setup was constantly being changed to accommodate the different products. This contributed greatly to the process problem. The apparent absence of major problems when stem grinding first began at KCP may only be attributed to the newness of the grinders.

Many other issues emerged as engineers and machinists began to scrutinize every component of the process. The first item of concern was the quality of the crush rolls. New England Carbide, Inc., the sole source of crush rolls for all KCP stems, had not provided a single roll that completely met the drawing specifications. Every roll was eventually deviated for acceptance after being returned to the vendor once or twice for rework. A Six-Sigma team was formed to identify methods to improve the quality of the crush rolls from the current source and to develop new sources for crush rolls. Later in 2003, engineering decided to make the arbor and the crush roll a single assembly to improve radial runout. This approach was effective in eliminating the cumulative error between the arbor and the crush roll.

Both crush grinders have been used for approximately eight years, to date. One was built using the last remaining components known to exist. The other was rebuilt in the mid-1990s. Machine logs showed that each machine had crashed severely at least once in the past eight years. Although many machine parts might have been worn, none had been identified for repair or replacement. Due to reduction in personnel, preventive maintenance had not been performed on these grinders.

In July 2003, KCP engineers requested service from United Grinding Technologies to diagnose the grey grinder. At first, the technician from United Grinding Technologies concluded that the KCP grinding process was not correct. After two days of thorough investigation, however, it was disclosed that two spindle alignment keys were damaged. These deformed alignment keys forced the spindle to be misaligned with respect to the crush roll and the work piece. In addition, the deformed alignment keys were not able to hold the spindle straight under the applied force during the crushing cycle. Calculations indicated that this force could have been up to 10,000 pounds. In the past, the machine had always been fixed when an obvious problem occurred. However, KCP engineering was not aware of this problem until they were notified. 
An important component that deteriorated but had been overlooked was the set of arbor block retention. This set of retention includes two alloy steel blocks that support and align the crush roll with the grinding wheel by the means of two journals located on both ends of the arbor. After many years of use, both locating surfaces of each block had grooved (see the figure below).

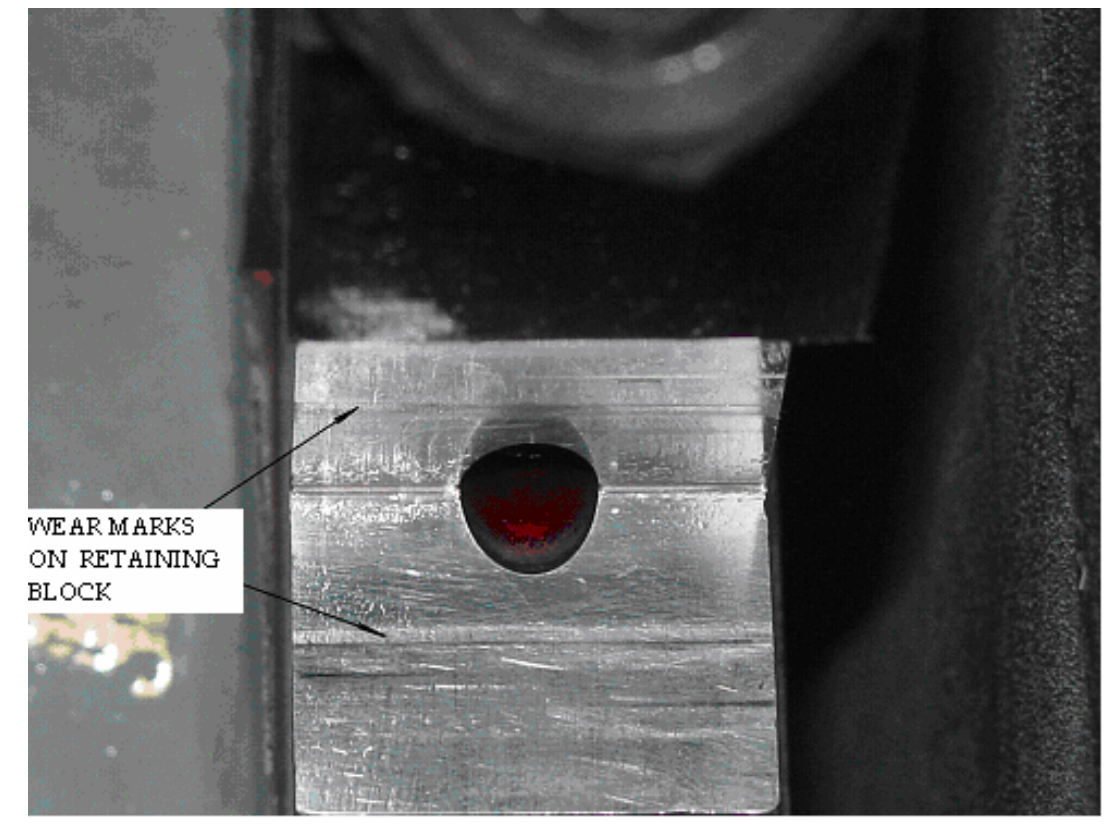

These grooves were wider and deeper on the inner sides close to the roll. By January 2004, arbor block retentions had been replaced in both grinders. The spindles of both grinders had also been realigned to the crush rolls.

Due to personnel changes, new machinists had to be trained to operate the machines and to follow work instructions. They monitored products using indicators, micrometers, and comparators. Similarly, engineers had been transferred or replaced. The replacement engineers had no knowledge of crush grinding. Together, engineers and machinists were able to use common practices to improve crush grinders that demonstrated low effectiveness. By the end of 2004, they had learned about and built a common understanding of diagnosing and controlling the crush grinding process. Many problems had been identified. Short-term solutions had been accomplished and long-term projects have been started.

Crush grinders in $\mathrm{D} / 025$ have ground acceptable products for many years. Due to production requirements, it is not practical to stop production to thoroughly inspect or rebuild grinders. The current strategy is to replace worn components at each service call. As a part of the Gas Transfer System expansion, a new grinder will be procured. When this new grinder is available for production, the existing grinders can be shut down for major rebuild (one at a time) without interrupting production. 


\section{Discussion}

\section{Scope and Purpose}

The purpose of this report is to identify, study, and understand key elements that affect the quality of stem production. Furthermore, this information provides guidance regarding controlling and optimizing the crush grinding process. In addition, this paper describes various troubleshooting methods used to learn more about basic techniques required in the crush grinding process. This knowledge is vital to help new engineers quickly understand crush grinding so they can adequately support machinists and stem production.

\section{Prior Work}

At the beginning of this work, formal crush grinding reports were not available in the Technical Information Center (TIC) at KCP. However, reports on crush grinding and a related topic were found in the files of a retired engineer who worked with crush grinders. The related topic, written by Dr. Marvin Burnham, documented his work on grinding while consulting with Rockwell International's Energy System Group in 1980s. In addition to this information, reports on grinding from the Society of Manufacturing Engineers (SME) and Manufacturing Engineering (ME) were found. In particular, the reports discussed the topic of creep-feed grinding.

In 1973, Douglas Vedoe (vice president of New England Carbide Tool Division) published a report in Modern Machine Shop titled "The Role of the Crush Roll." In general, all of the reports provided good information about crush grinding. However, crush grinding at KCP is unique since sharp corners and tight tolerances are processed on thin-walled parts. Therefore, specific problems could not be resolved by reading these reports. Specific reports on crush grinding are essential to teach engineers how to continuously control future product production.

\section{Activity}

Machinists and engineers in the Gas Transfer System (GTS) department have worked extensively to identify many crush grinding issues at KCP. Through the knowledge gained from technical reports, engineers have been able to troubleshoot and improve the process. This section will review some past activities, specifically providing details for those that occurred from mid-2003 to mid-2005.

\section{Background}

The crush grinding process was transferred from the Rocky Flat plant in Colorado to KCP in the mid-1990s. By 2002, KCP engineers who participated in the transfer were either retired or promoted. A sketch from an old record (dated 1989) showed that the ground stem had always been swollen in the middle. This common problem is still prevalent. In fact, as the swell size increases, the stem length increases, also. Engineering allowed stems to be ground in this condition until the swell reached 0.0018 inches. Then, the crush roll would be replaced. The $1 \mathrm{X}$ stem is the longest and has the most edges and diameters. Variations in diameters and their 
lengths cause concentrated stress on localized weak sections of the stem. Along the entire profile to be ground on the $1 \mathrm{X}$ product, the biggest diameter is $460 \%$ larger than the smallest diameter. In contrast, the largest diameter's length is only $6 \%$ larger (approximately) than the smallest diameter's length. As a result, this is the most difficult product to grind.

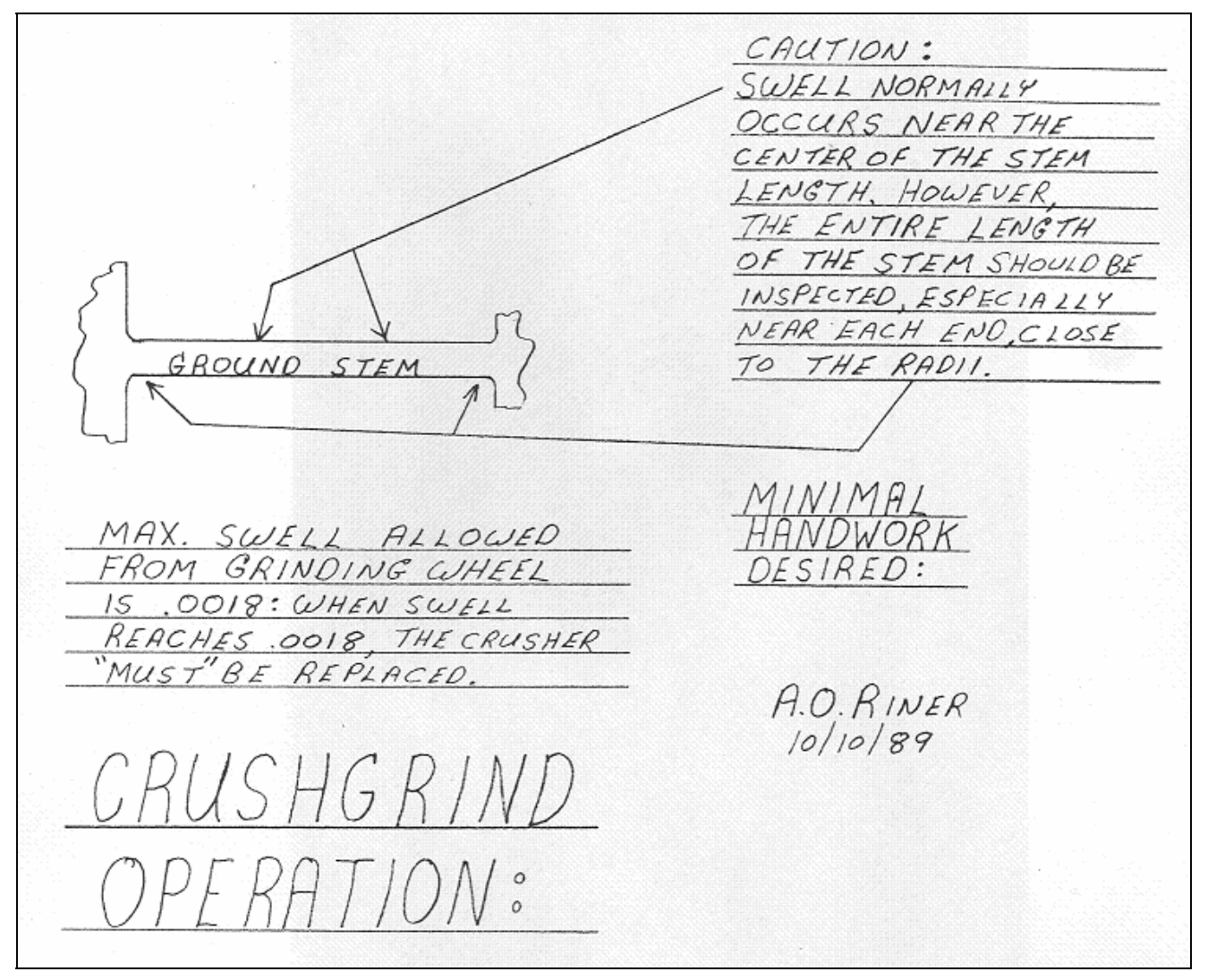

Figure 1. A record of instruction in 1989 to handle swelling of stem.

Similar to radial dimensions (diameters) of products, lateral dimensions (lengths) are difficult to control. Increasing groove width has been the common fault in lateral dimensions. Machinists either top dressed the wheel and reformed it or prematurely changed the crush roll to remedy this situation. It appeared to solve the problem or, at least, reduce it. Unfortunately, this resulted in a higher rate of grinding wheel and crush roll wear. Over time, the problem became a daily phenomenon. None the less, machinists kept grinding products at a low feed rate to reduce radial and lateral errors. This practice seemed to help.

The design of crush rolls was based on similar, pre-existing crush rolls. Crush rolls could be optimized by measuring resulting product dimensions and adjusting them to more accurately meet the product specification. Methods are not currently available to estimate the precision of transferring dimensions from the crush roll to grinding wheel and, finally, to the work piece. 
New England Carbide, Inc., inspected crush rolls with a 50X comparator. Although the machinist's skill was not in question, the inspection method was not adequate to verify the required accuracy. KCP crush rolls were not a primary product for New England Carbide. As a result, the company was not financially motivated to invest in more sophisticated equipment.

The grinding wheel arbors, crush-roll arbors, and grinders were originally procured from Sheffield. However, United Grinding Technologies, who purchased Sheffield, is the company with which KCP is currently dealing. Unfortunately, maintenance records for arbors were neither kept nor recommended. Currently at KCP, a plan or schedule does not exist that provides direction to check or replace these arbors as they wear out. Recently, KCP implemented a program to replace worn crush-roll arbors. Ironically, it was discovered that new crush roll arbors from the United Grinding Technologies could not meet the quality specifications. For example, six new crush roll arbors were purchased in 2004 . However, four of these crush rolls were returned to the manufacturer three times for rework. The crush roll that did not require rework could not hold the TIR to complete even a single lot of product (average lot of 24 parts).

\section{$\underline{\text { Adjust crush roll design }}$}

A crush roll had been used to grind the $1 \mathrm{X}$ stem. This crush roll was modified from a crush roll with a similar configuration. The new crush roll is the most complicated configuration.

Therefore, the $1 \mathrm{X}$ stem is the most difficult stem to crush grind. The overall length of the profile is 2.886 inches. There are three diameters, a couple sharp corners, and fillets to be formed. The groove feature on the cone of the crush roll has always been the center of attention regarding quality. The groove was positioned too far from datum B, which caused problems in the roll design (see figure 2 below).

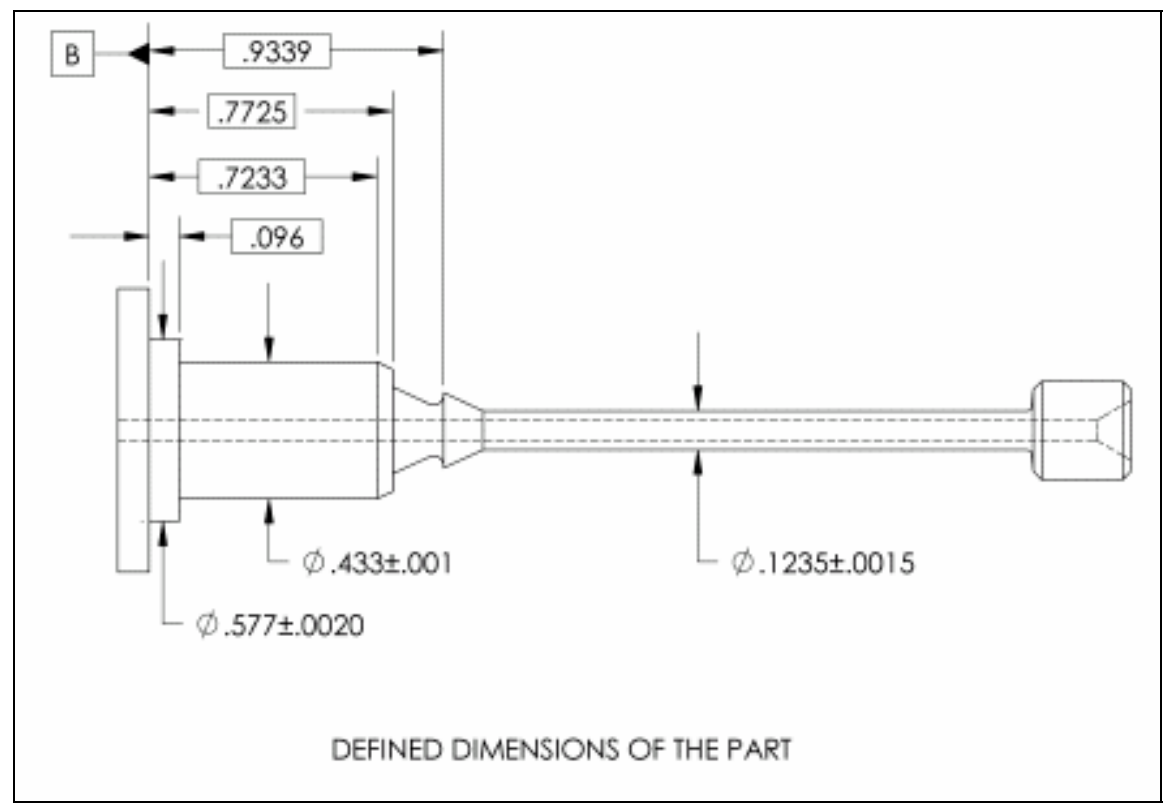

Figure 2. Key dimensions of the $1 \mathrm{X}$ stem. 
A study was performed to characterize the problems associated with the $1 \mathrm{X}$ stem. The dimensions on a selected crush roll were inspected and recorded. The roll was then used to crush form a grinding wheel. In turn, the wheel was used to grind three specimens for dimensional study. Three selected lateral dimensions were measured on each specimen and compared to the same lateral dimensions on the crush roll. In addition, the measured dimensions were also compared to the part drawing (see table 1 below).

Table 1. Measurements of specimen using old crush roll.

\begin{tabular}{|l|c|c|c|c|c|c|c|}
\hline \multirow{2}{*}{ Features } & Specified & Crush Roll & Crush Roll & \multicolumn{4}{c|}{ Comparator Measurements } \\
\cline { 5 - 8 } & Dimension & Design & Inspection & Meas. \#1 & Meas. \#2 & Meas. \#3 & Average \\
\hline Step & $\mathbf{0 . 0 9 6 0}$ & $\mathbf{0 . 0 9 6 8}$ & $\mathbf{0 . 0 9 7 0}$ & $\mathbf{0 . 0 9 7 5}$ & $\mathbf{0 . 0 9 7 3}$ & $\mathbf{0 . 0 9 7 9}$ & $\mathbf{0 . 0 9 7 6}$ \\
\hline Groove Step & $\mathbf{0 . 7 7 2 5}$ & $\mathbf{0 . 7 7 3 6}$ & $\mathbf{0 . 7 7 3 7}$ & $\mathbf{0 . 7 7 3 9}$ & $\mathbf{0 . 7 7 3 5}$ & $\mathbf{0 . 7 7 4 6}$ & $\mathbf{0 . 7 7 4 0}$ \\
\hline Groove Tip & $\mathbf{0 . 9 3 3 9}$ & $\mathbf{0 . 9 3 3 6}$ & $\mathbf{0 . 9 3 2 9}$ & $\mathbf{0 . 9 3 8 5}$ & $\mathbf{0 . 9 3 9 0}$ & $\mathbf{0 . 9 3 8 7}$ & $\mathbf{0 . 9 3 8 7}$ \\
\hline
\end{tabular}

The first point to consider for this crush roll was that the 0.0960 -inch and the 0.7725 -inch dimensions from datum B were designed to be larger on the crush roll ( 0.0968 inches and 0.7736 inches). All three measurements for each dimension were equal to or larger than the dimensions of the roll. This meant that the design dimensions should be changed to be closer to the part dimensions. As a result, the design dimensions for new crush roll TC423230-004 were 0.0965 inches and 0.7730 inches. The difference of 0.0005 inches provided allowance since the crush roll wears down each time it is crushed.

In comparison to the two dimensions presented above, the 0.9339-inch dimension was observed to "grow" more as evident from the comparator measurements. By definition, a surface is represented with a normal vector outward. The direction of this vector determines the orientation of the surface.

The surfaces of the 0.0960-inch and 0.7725-inch dimensions on the form are parallel with the surface of datum B (illustrated by surfaces A and B, respectively, in figure 3). However, the surface of the 0.9339-inch dimension is opposite that of datum B (as surface C to surface A). Parallel surfaces are ground on the same sides by loosing grids; therefore, their distances are almost the same during the transformation process. Opposite surfaces are ground on opposite sides during the transformation. As a result, the distance will grow by the total amount on each surface. The phenomenon is amplified if the roll or, especially, the grinding wheel is wobbling. Thus, distances would "grow." The measurements of the 0.9339-inch dimensions shown in table 1 are out of limits (0.9309 to 0.9369 inches). This results from the combination of crush roll design and wheel wobbling. 


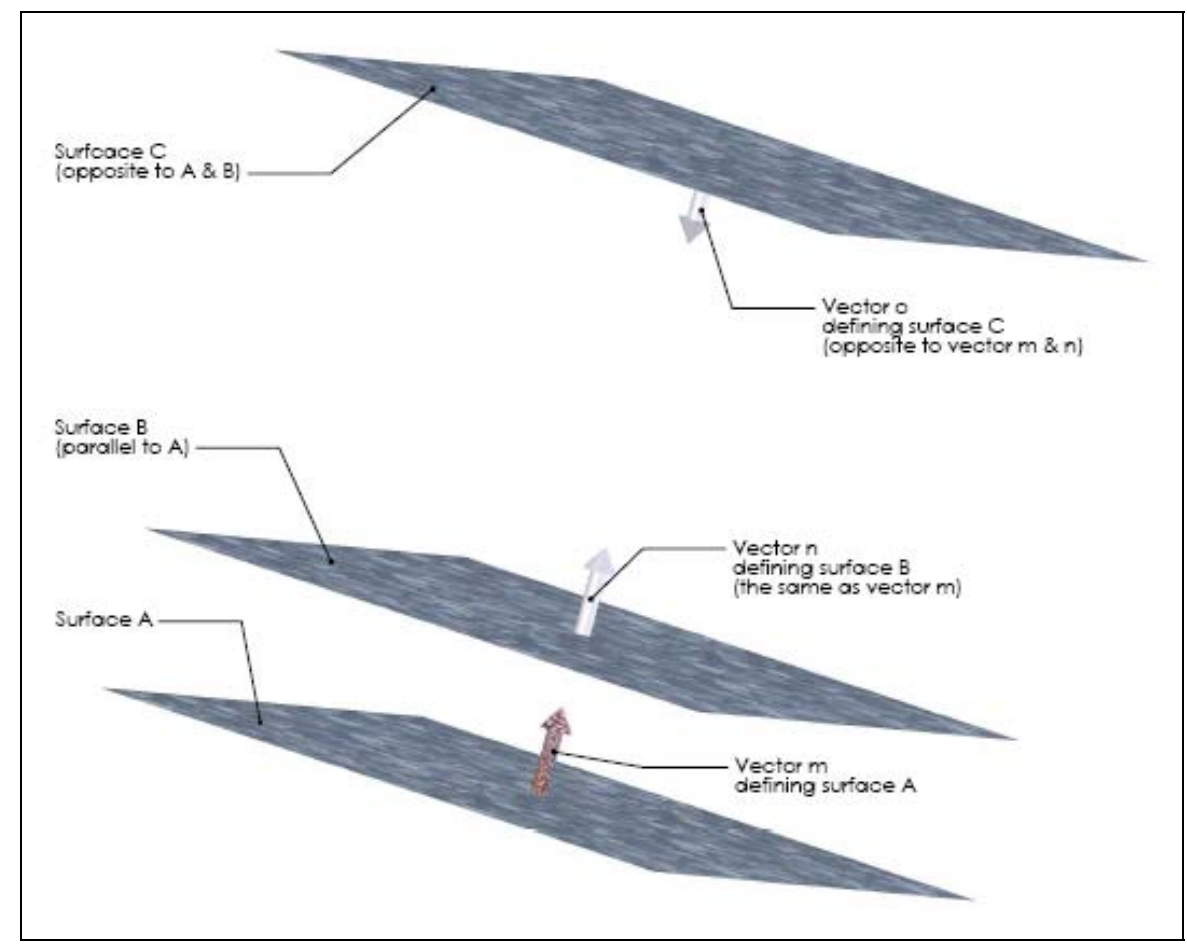

Figure 3. Surface definition and relationship. Surface A \& B are coupled - the distance will not change. Surface $C$ is decoupled to A \& B - Distance from surface C to surface A (or B) will increase during the transformation of crush grinding.

The three basic dimensions of 0.0968, 0.7736, and 0.9336 inches on the drawing were adjusted to $0.0965,0.7730$, and 0.9320 inches on the TC423230-004 drawing. The three grind sample measurements recorded in table 2, below, show the result of the change on the final product form. The average dimensions are closer to the design dimensions of the final product. In particular, the adjustment from 0.9336 to 0.9320 inches (-0.0016 inches) changed the average dimension on the part from 0.9387 to 0.9335 inches. Recall that the limits of these dimensions are 0.9309 inches and 0.9369 inches. This adjustment allows more parts to be ground between crushes and reduces the effect of worn machine tool components.

Table 2. Measurement of adjusted dimensions for crush roll.

\begin{tabular}{|l|c|c|c|c|c|c|c|}
\hline \multirow{2}{*}{ Features } & Specified & Crush Roll & Crush Roll & \multicolumn{3}{|c|}{ Comparator Measurements } \\
\cline { 5 - 8 } & Dimension & Design & Inspection & Meas. \#1 & Meas. \#2 & Meas. \#3 & Average \\
\hline Step & $\mathbf{0 . 0 9 6 0}$ & $\mathbf{0 . 0 9 6 5}$ & $\mathbf{0 . 0 9 6 7}$ & $\mathbf{0 . 0 9 6 2}$ & $\mathbf{0 . 0 9 6 2}$ & $\mathbf{0 . 0 9 6 4}$ & $\mathbf{0 . 0 9 6 3}$ \\
\hline Groove Step & $\mathbf{0 . 7 7 2 5}$ & $\mathbf{0 . 7 7 3 0}$ & $\mathbf{0 . 7 7 3 2}$ & $\mathbf{0 . 7 7 2 7}$ & $\mathbf{0 . 7 7 2 8}$ & $\mathbf{0 . 7 7 2 4}$ & $\mathbf{0 . 7 7 2 6}$ \\
\hline Groove Tip & $\mathbf{0 . 9 3 3 9}$ & $\mathbf{0 . 9 3 2 0}$ & $\mathbf{0 . 9 3 2 8}$ & $\mathbf{0 . 9 3 3 6}$ & $\mathbf{0 . 9 3 3 6}$ & $\mathbf{0 . 9 3 3 3}$ & $\mathbf{0 . 9 3 3 5}$ \\
\hline
\end{tabular}

Another element of this complicated crush roll is tolerance "build up". The implementation of a crush roll assembly was required to reduce the addition of error from the arbor to those of the crush roll. The outside diameter of the arbor varies from 1.9998 to 2.0000 inches while the 
inside diameter of the crush roll varies from 2.0000 to 2.0002 inches. This results in the maximum tolerance of 0.0004 inches between the arbor and the roll. Even if the profile on the crush roll was perfect, the combined assembly of arbor and crush roll would still have a runout of 0.0004 inches.

Figure 4, below, illustrates the worst case scenario when assembling a crush roll on an arbor. The 0.0004-inch tolerance at each end will cause a barrel shape on the grinding wheel. This shape transfers onto the part causing a concave shape on the stem of up to 0.0008 inches $(0.0004$ inches per side). Machine tool condition, wheel loading, and cutting conditions will contribute to this situation, thus amplifying the error. The diameter tolerance for the $1 \mathrm{X}$ stem is $+/-0.001$ inches. Therefore, holding this tolerance with this assembly is extremely difficult and, in some cases, impossible.

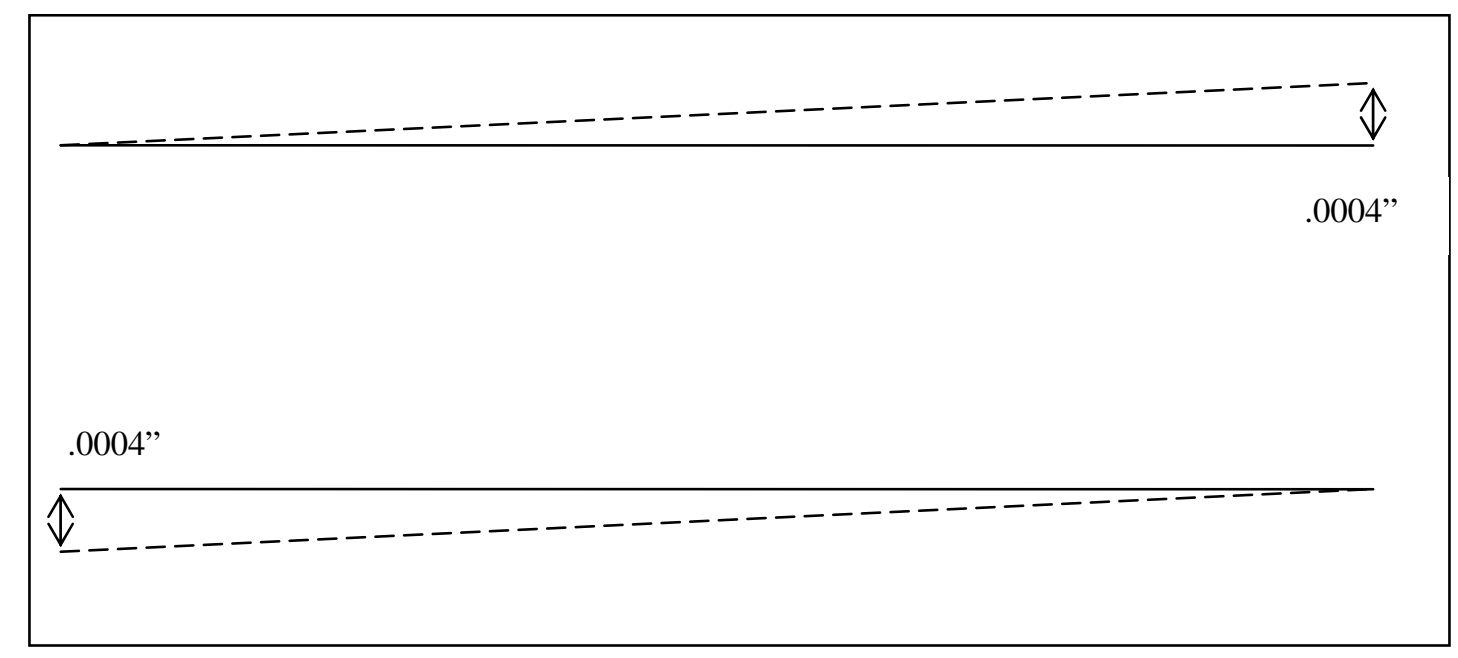

Figure 4. Illustration of total (build-up) tolerance in the worst case of assembly

\section{Grinding wheel spindle}

The spindle of a grinder is the most important component of the machine. The total applied force on the spindle can be up to 10,000 pounds during the crush-forming cycle. A crush grinding machine, therefore, must have a very rigid spindle. In the crush grinding process, the profile of final product is formed on the wheel by a crush roll. The crush roll is made of carbide and its configuration is an approximate copy of the final product. This approximate copy is designed based on the number of features to be ground, complication of the profile, and experience.

The previous section discussed the experience required to design a workable transformation of dimensions. The accuracy of this transformation process mainly depends on the rigidity of the grinding wheel spindle. Grinding wheel balance keeps the spindle stable. A new wheel is always diamond dressed before being crush formed. Diamond dressing involves truing the wheel with a single point diamond to make it concentric with the grinding spindle. Side dressing may sometimes be required to correct a wobbling wheel. 
As illustrated in figure 5, below, crush-form grinding is a process of transforming a form among three entities. The grinding wheel copies a defined form from the crush roll and reprints this form onto work pieces. Understanding and controlling a crush grinding process requires more knowledge than a typical cylinder grinding process.

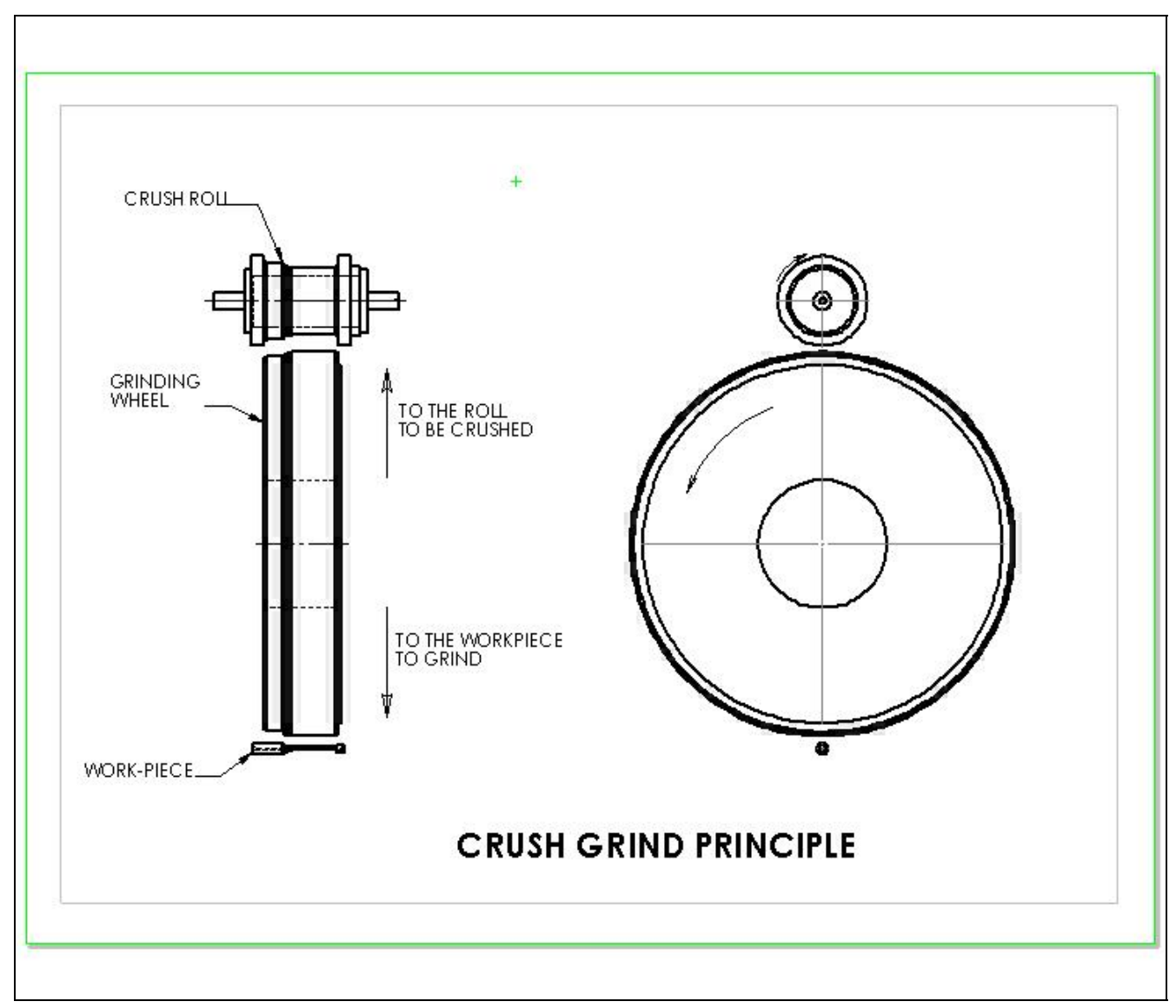

Figure 5. Schematic of the crush grinding principle.

Two situations had been identified that could have affected spindle alignment or rigidity. In the first case, it was discovered that the spindle was misaligned. In July 2003, a technician from United Grinding Technologies (working with an equipment engineer) learned that the grinding wheel tilted 0.005 inches over the face of a 3.00-inch wide grinding wheel. The alignment key of the housing had an indentation, evident from a past crash. The crash forced the high side of the grinding wheel into the crush roll. Therefore, the spindle system could deflect under the tremendous pressure of the grinding process. As a result, the forms radially opposed (across the center line of the grinding wheel) were not aligned with each other. This made it appear that the grinding wheel was wobbling. These forms, from a local perspective, were correctly transformed from the crush roll. However, they widened the form on the product during grinding. 
In the second case, the spindle bearings had worn beyond design limits. The grinding spindle was designed to have 0.0002-inch maximum lateral motion along its axis. With a 16.0-inch diameter (8.0 inch radius, maximum) grinding wheel, this lateral motion could be magnified up to a 0.0016 -inch $(0.0002 \times 8.0$ inch $)$ misalignment at the edge of the wheel. Tapered surfaces on the crush roll, designed to easily position the grinding wheel to the form, tended to maximize the misalignment. The results were difficult to predict due to different inputs of spindle rigidity, wheel strength, and wheel size. Uniformity of the surfaces on both sides of the wheel played an essential role in this misalignment. Even-hardness on both sides allowed the same deflection. Softer or harder sides would deflect less or more, respectively. As a result, the error would be asymmetrical.

In December 2004, grinder CE\#83819 was diagnosed with 0.0007-inch lateral motion. As an ultimate result, the grinding wheel for the $1 \mathrm{~K}$ product was wobbling 0.0030 inches. Measurements showed that the grinding wheel wobble was four times greater than the lateral motion of the wheel. This effect caused more material to be crushed near the edges of the face of the grinding wheel (see figure 6 below). It must be noted that this phenomenon will be magnified if the arbor is also wobbling.

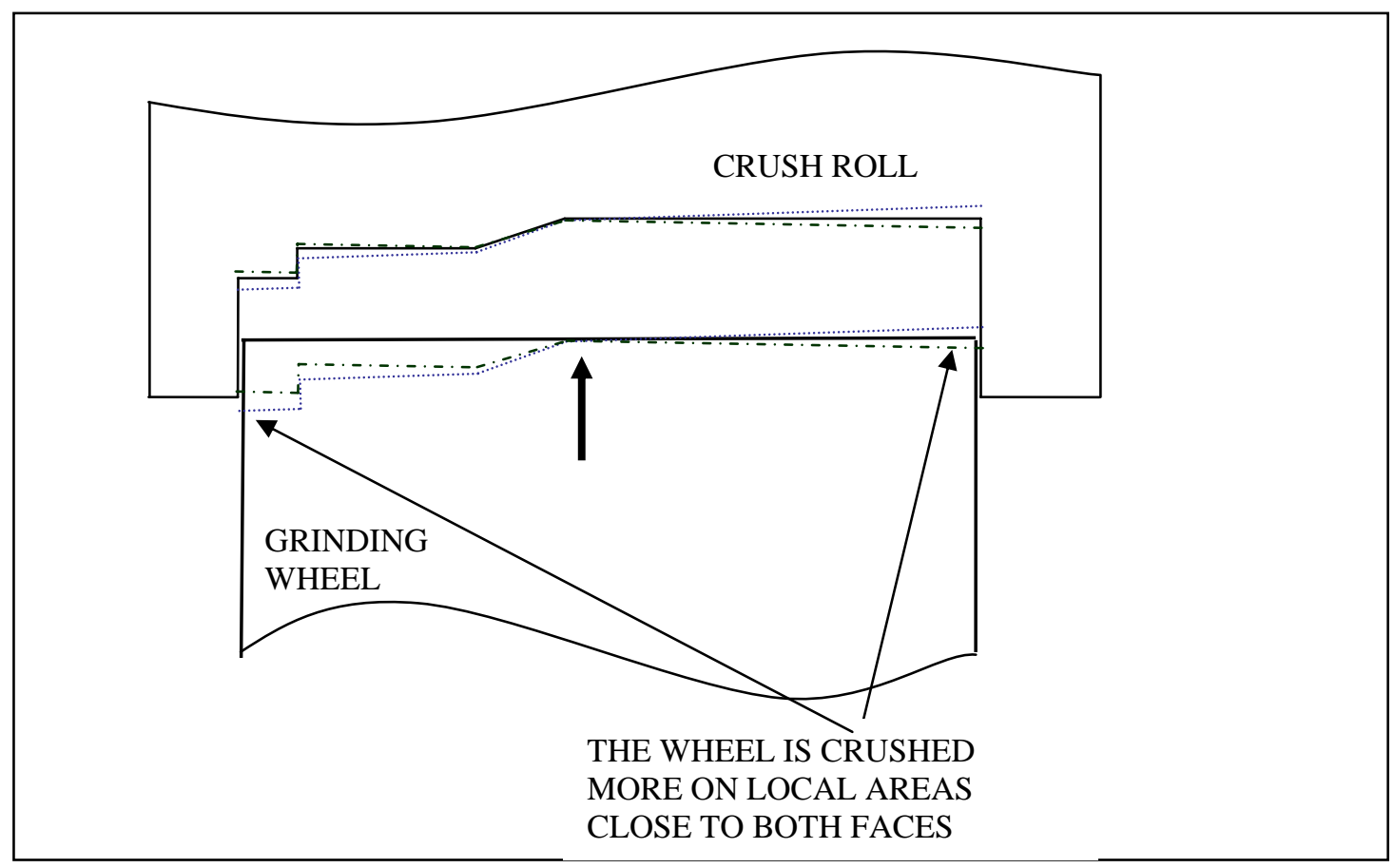

Figure 6. The effect of misalignment on the grinding wheel.

\section{What else can be wrong?}

Listed below are direct input and corresponding output parameters for the crush grinding process at KCP. Part inconsistency has been accepted in the past as normal process behavior. Product variance has been overlooked until the outputs were generated outside of specification limits. 
Proper attention to setup details (inputs) will improve the entire crush grinding process and reduce the variance of product.

\begin{tabular}{|c|c|c|}
\hline \multirow{2}{*}{\multicolumn{3}{|c|}{$\frac{\text { INPUT }}{\text { Crush form }}$}} \\
\hline & & \\
\hline \multicolumn{3}{|l|}{ Crush roll arbor } \\
\hline \multicolumn{3}{|l|}{ Parallelism } \\
\hline Wheel material & & Surface finish \\
\hline Roll material & & Form accuracy \\
\hline Part material & CRUSH GRINDING PROCESS & Dim. Tolerance \\
\hline Wheel spindle & & Part consistency \\
\hline \multicolumn{3}{|l|}{ Work-piece collet } \\
\hline Live center & & \\
\hline Jet wheel & & \\
\hline
\end{tabular}

The five components that most often cause bad form on products are the wheel, roll, work piece, motor, and belt. The results can be affected by a single component or a combination of components. It is a challenge to correctly perform troubleshooting when the grinder is in poor condition. The defects caused by the individual components are discussed next.

The wheel should have a grit size small enough to achieve the required surface finish as well as define sharp corners and radii. If the grit is too fine, however, it is difficult to remove the ground material from the grinding surface. This often gums up the wheel and heats up the work piece. Work hardening and/or deformed stems are the direct results of this effect. In some instances, the plane face of work pieces can be burned. This is especially the case when the feed rate is slow. The list below outlines some defects and causes related to the grinding wheel.

\begin{tabular}{|l|l|}
\hline \multicolumn{1}{|c|}{ Defects } & \multicolumn{1}{c|}{ Causes } \\
\hline Form Breakdown & $\begin{array}{l}\text { Bearings of grinding wheel } \\
\text { required adjustment }\end{array}$ \\
\hline & Wheel grade is too hard \\
\hline & $\begin{array}{l}\text { Wheel adapter flanges need } \\
\text { tighten to proper tension }\end{array}$ \\
\hline & High RPM on the wheel \\
\hline & Hard grade wheel \\
\hline Part burning & Fine grain wheel \\
\hline & \\
\hline Poor surface finish & Coarse grain wheel \\
\hline
\end{tabular}

Should read Wheel adapter flanges not tightened to proper tension

The roll is considered the heart of the crush grinding process. Without good quality crush rolls, the process stops. A nonconforming form results in fast wear or nonconforming products. KCP has never had crush rolls that conformed to the specifications. Two defects and causes related to the crush roll are listed below. 


\begin{tabular}{|l|l|}
\hline \multicolumn{1}{|c|}{ Defects } & \multicolumn{1}{c|}{ Causes } \\
\hline Form Breakdown & Loose crush arbor \\
\hline & \\
\hline Pattern on roll and wheel & Wear or flat spot in bearings \\
\hline
\end{tabular}

The work-piece material is the only component that cannot be controlled in the crush grinding process. If the work piece has a non-uniform microstructure or hard spots, deviations will occur in the length and/or roundness. The worst-case deviation recorded was a 0.002-inch difference in diameter between two measurements taken at 90 degrees apart along any height of the stem. The plane surface between these two diameters ( 0.577 inches and 0.900 inches) had two distinct finishes.

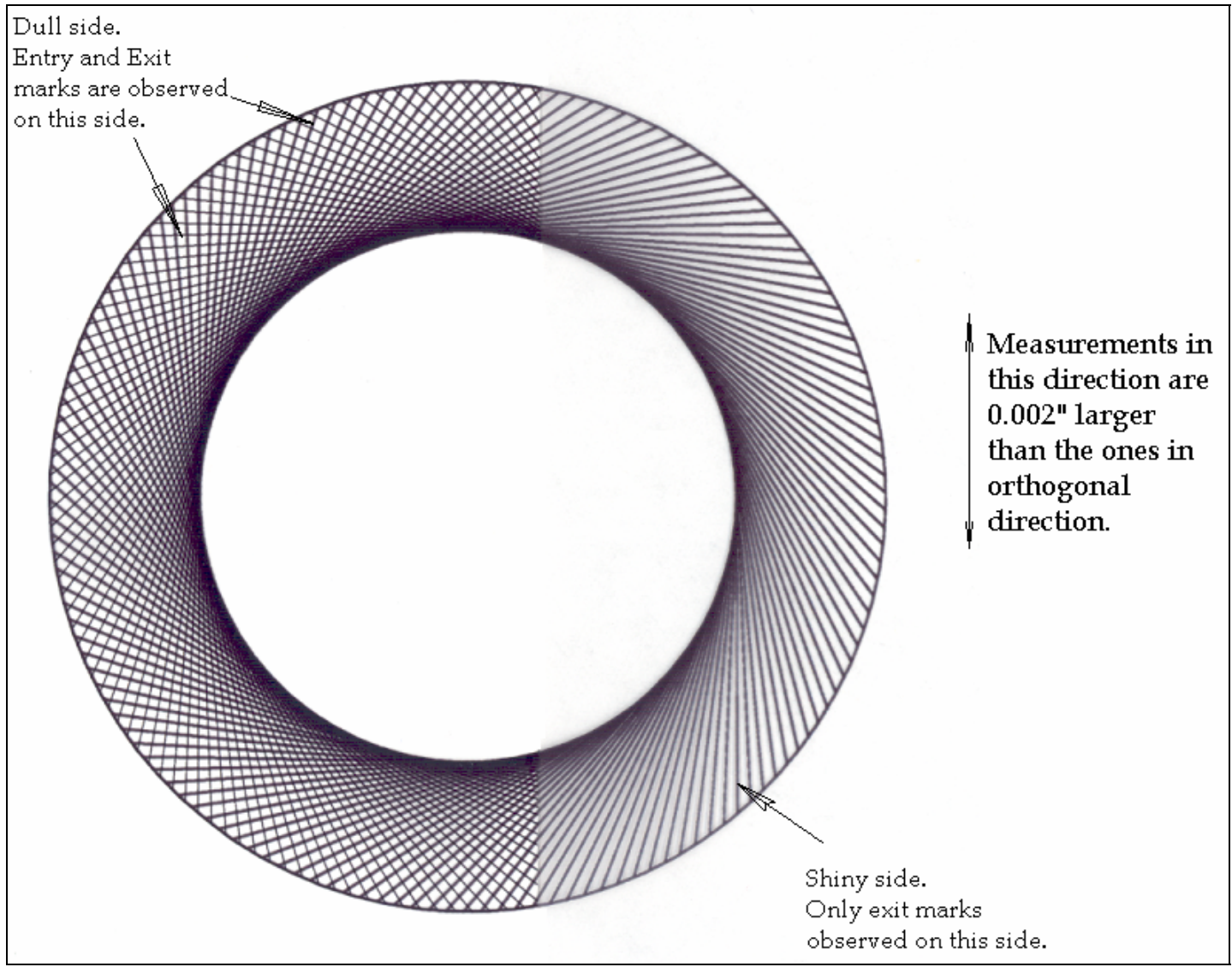

Figure 7. Illustration of ground surface. Nonuniform material is believed to be the reason for this appearance.

A micro-hardness test and a micro-grain structure analysis showed no difference from one side to the other. However, a Laser Induced Breakdown Spectrometer (or simply Laser Ablation) test a technique of shooting a laser beam onto a specimen to break all atom bonds, then counting isotopes of each element in a material - showed that the stainless steel on the dull side had more isotopes in every element than those counted on the shiny side. This indicated that it was harder 
to break bonds among atoms on the shiny side since it was more compact and harder. The surface finish of the dull side was normal. More tests will be performed to research this phenomenon.

The machine motor has a dual effect in the crush grinding process since it is employed to crush form the wheel and, then, to grind the work piece. An unbalanced motor causes lofting of the wheel or humming. As a result, the form will not transform properly onto the wheel and, then, onto the work piece.

When the belt slips, the wheel stalls and the process fails. A slipping belt can cause wheel wobbling and flat spots on the crush roll and the grinding wheel. This results, ultimately, in patterns on the wheel, egg-shaped parts, and/or nonconforming dimensions.

Another component to be considered in the crush grinding process is the jet wheel cleaner. The jet wheel cleaner's position is set 0.03125 to 0.0625 inches from the wheel surface. The cleaner shoots a continuous stream of high pressure coolant (oil) onto the face of the grinding wheel to remove stainless steel particles from its porous pockets. The following table, which was extracted from the instruction manual for the Bendix Model 187-B Crush Grinder (manufactured by Sheffield), lists defects and causes related to the jet wheel cleaner.

\begin{tabular}{|l|l|}
\hline \multicolumn{1}{|c|}{ Defects } & \multicolumn{1}{c|}{ Causes } \\
\hline Form Breakdown & Coolant maybe dirty \\
\hline & \\
\hline Part burning & Low Coolant flow \& pressure \\
\hline & \\
\hline Poor surface finish & Coolant maybe dirty \\
\hline & Clogged Jet wheel cleaner \\
\hline
\end{tabular}

In addition to the items listed in the table above, a common problem associated with the jet wheel cleaner is the incorrect positioning of the coolant stream on the grinding wheel. This causes the grinding wheel to become dirty or overloaded, thus burning the corresponding workpiece surface. With proper positioning of the coolant stream, however, this problem can effectively be eliminated.

The coolant can also affect proper forming during crush grinding. If the coolant tube is clogged, broken particles will not be removed from the grinding wheel and the crush roll. This effect will quickly break the form. The hydraulic pumps, which provide pressure to shoot the coolant, can also affect coolant flow. The machinist should monitor jet wheel cleaner pressure during the operation to guarantee proper wheel cleaning.

During this study, it was interesting to learn about the importance of the sealing of a collet face. Some collets transferred from the Rocky Flat plant were designed with three open access holes used to tighten the closer. During the grinding process, particles easily get through these holes and settle down to the mating surfaces in the collet assembly. Each time the collet is opened or 
closed, these particles get into the gap of the locating surface (the part to collet interfaces). The particles push the collet off center resulting in concentricity failure. As expected, the wider the holes, the greater the amount of particles that enter. This decreases the chance stems of grinding stems concentrically with respect to the gun-drilled hole.

\section{Crush roll arbor availability}

KCP purchased six new crush roll arbors from United Grinding Technologies from late 2003 to early 2004. The first two arbors were assembled. After the last four were purchased and sent to the vendor to make two more assemblies and two new assemblies, KCP engineers were informed by the vendor that these arbors would not hold the assembly to the specifications. According to a senior engineer from United Grinding Technologies, these arbors must have a 0.0002 -inch TIR (maximum). The last four arbors had been sent back to United Grinding Technologies three times for rebuild because they failed TIR requirements. Three arbors finally met the requirements and the remaining arbor was deviated.

The four arbors were then sent to two New England Carbide and Martel Tool. Two of these arbors failed, again, when New England Carbide tried to finish two assemblies. The third crush roll arbor assembled had a 0.004-inch TIR after being used to finish three product orders. A typical crush roll can be used to grind five or more product orders. Another arbor was also bad and had to be rebuilt at Martel Tool. From this event, it was concluded that crush roll arbors from United Grinding Technologies can no longer provide KCP with the needed service.

Martel Tool has performed an extensive study to build arbors for KCP. A prototype arbor was completed and accepted in February 2005. However, a trial has not been carried out on this prototype arbor. The second arbor is expected to be built in TC423230-004 serial \#2 and should be shipped to KCP by late March 2005. Martel Tool is expected to be the main provider of arbors and crush rolls for $1 \mathrm{~K}$ and $1 \mathrm{X}$ products.

\section{Accomplishments}

Machinists and engineers have learned a great deal about and gained significant knowledge of crush-form grinding. To succeed in crush-form grinding, a rigid machine is essential. All efforts to troubleshoot the grinding machine will be futile if machine components are excessively worn or do not meet specifications. Two problems with the wheel spindle have been identified. First, the spindle was not parallel to the crush roll. To alleviate the problem, the alignment keys were replaced. Second, the original bearings wore out after more than 10 years of service. As of March 2005, one set of bearings were scheduled to be installed on one grinder and another grinder is scheduled to be fixed in the near future.

Crush rolls with the complicated $1 \mathrm{~K}$ and $1 \mathrm{X}$ profiles have been revised to adjust tolerances. In addition, they have been redesigned so that they may be assembled with arbors prior to vendor finishing. The assemblies will eliminate the tolerance build-up of the arbor's outside diameter and the crush roll's inside diameter. Martel Tool will be KCP's sole source for the arbors and crush rolls that are used to produce the $1 \mathrm{~K}$ and $1 \mathrm{X}$ stems. 
A special indicator was made to verify the parallelism of wheel spindle to the arbor during the setup. This practice guarantees a good setup, eliminates any guess work, and aids in trouble shooting. The benefits of the special indicator are significant since the machinist immediately knows the condition of the machine. As a result, the trial-and-error time associated with determining and correcting related problems is eliminated.

\section{Future Work}

The two crush grinders in D/025 have been used for many years. From 2003 to 2005, KCP engineers have learned that there are multiple signs indicating wear on components. A new crush grinder is planned to be in service by the end of 2005. However, the two existing grinders will need to be rebuilt in the next two to three years.

Also, an alternate method of process is valuable to research. Currently, United Grinding Technologies is the only company who will custom build crush grinders for the Kansas City Plant. KCP's machine repair department can provide only limited support on parts and technology for the existing crush grinders. 


\section{References}

Bibliography

Accuracy Concerns in Crush Dressed Form Grinding.

Report of Consulting Services Provide to Rockwell International. August 1988.

Form Grinding - The role of the Crush Roll. Modern Machine Shop. December 1973. 